\title{
Effect of an Teaching Program on Critical Care Nurses's Performance About end of Life Care for Hepatic Patients
}

\author{
Nagat Hussien Nasr ${ }^{1}$, Nabila Faiek Ameen ${ }^{2}$, Mona Aly Mohammed ${ }^{3} \&$ Amal Ismail Abd El hafiz . \\ 1. B.SC.N Faculty of Nursing, Assuit University Hospital, Egypt. \\ 2. Professor of Internal Medicine \&Gastroenterology Faculty of medicin, Assuit University, Egypt \\ 3. Assist Professor Critical Care Nursing Faculty of Nursing, Assuit University, Egypt. \\ 4. Lecture of Critical Care Nursing Faculty of Nursing Assuit University, Egypt .
}

\begin{abstract}
Background: National End of Life Care featured that most patients (>70\%) of hepatic disease dying from liver disease. In this manner there is have to expand familiarity with basic of critical nurse's performance aboutend of life care of hepatic patients. Aim: Present study aimed to evaluate the effect of teaching program on critical care nurses Performance about end of life care for hepatic patients. Setting: Study was led in Intensive care units at El Raghy University Hospital. Subjects: Fourty nurses were included in the study. Tools of data collection: there are two tools used to collect data: (Tool l) Knowledge assessment questionnaire (Tool II) observational check list. All nurses divided into small group and received the teaching program. Evaluate nurses performance Pre and post test was complete immediately after program implementation. Results: There is very highly statistical difference between nurses' knowledge in Pre \&Post test program ( $\mathrm{p}<0.05)$. Most of nurses had unsatisfactory level preknowledge with percentage (77.5\%); Also most of Post Study group had satisfactory level with percentage (90.0\%). Conclusion: strengthening of basic care nurses knowledge and practices would have a positive impact on their knowledge and practice. Recommendation: Provide education through end of life Nursing Education Consortium modules for all critical care nurses.
\end{abstract}

\section{Keywords: Critical Care Nursing, End of life care, Hepatic Patient \& Teaching Program.}

\section{Introduction}

Chronic liver disease is a major cause of mortality worldwide. In the United Kingdom, liver deaths have been increasing for 30 years and currently constitute the fifth highest cause of mortality. (Moore, 2012). Chronic liver diseases (CLDs) represent a major world public health problem. The liver is in many ways, the reflection of a person's health and should play a central role in worldwide public health policies. Current, but probably undervalued, worldwide, estimations show that 844 million people have CLDs, with a mortality rate of 2 million deaths per year (Byass, 2014)

End-stage liver disease (ESLD) is the lasted compensating phase in the liver trajectory. It is characterized byepisodic, acute exacerbations, frequently requiring.hospitalization. Include the following complications for example variceal hemorrhage or hepatoma, combined with different side effects including ascites, extraordinary weakness, pruritus, and cachexia. (D'Amico, et al., 2012).

Nurses play a pivotal role in managing patients' pain and the associated distress which affects the comfort of critical patient. The nurses' roles in pain management such as assessment, implementation of evidence-based management strategies, monitoring patients' response, documentation and educating of the patients and their families are key to successful pain control. (Dunwoody, et al., 2008).

Basic care nurse in critical unit need require openings through instruction and mentoring to build up their competency in providing end-of-life care around the areas of: communications skills to advocate for patients and families, standardized approaches to pain and symptom management and seeking and providing emotional support to patients, families and members of the health care team. (Bach, et al., 2011).

Patients toward the finish of life in the emergency unit is(ICU) is highly dependent on the ICU nurse's knowledge and skill about comfort level in watching over the withering patient and the patient's family. Considering that few medical attendants get formal preparing in end-of-life mind, medical attendants may see the look after their patients and families. (Mary, 2014).

Also nurses play an important role in facilitating communication between and among family members and the health care team. The strategies nurses use to enact this role are presented in three categories: give information to physicians, give information to family members, and mediate. (Judith, 2011).

Nurses provide support to families by taking time to develop trusting relationships. Family members reported that they trusted nurses who introduced 
themselves to the family, explained equipment, and were willing to talk Nurses also identified the importance of establishing a rapport with families. (Calvin, et al., 2009).

Prevalence of hepatic

In Egypt there is almost certainly that chronic liver illnesses are a major health concern. Hepatitis $\mathrm{C}$ virus (HCV) predominance among the 15-59 years age group is evaluated to be $14.7 \%$. The high predominance of constant liver illnesses has prompted expanding quantities of Egyptian patients experiencing end arrange liver disease (ESLD), requiring liver transplantation. (Khaled \& Ibrahim. 2016).

Statistic of tropical and gastrointestinal intensive care units at El Raghy University Hospital in the year of (2016) revealed that the number of patient admitted with liver cirrhosis, hepatic coma were 700patients (hospital record of El Raghy University Hospital).

\section{Aim of the study}

The present study aimed to evaluate the effect of an teaching program on critical care nurses Performance about end of life care for hepatic patients

\section{Significance of the study}

Liver is a vital organ with many functions including: metabolizing carbohydrates, fats and bilirubin, storing glycogen, and cleansing blood. The cirrhotic liver may be able to function adequately termed a "compensated" liver - but once the functions start to deteriorate and complications of portal hypertension arise, it is "decompensated" and the patient has end stage liver disease.( Moore, 2012).

Nurses from all areas of practice must be able to offer health information and education to patients to raise awareness of liver disease and promote healthy living strategies. So there is a need to increase knowledge and practice of critical care nurses about end of life care for hepatic patients

Increasing numbers of patients with liver disease are presenting in general practice and emergency departments. It is important that nurses understand the common causes and complications of liver disease Thus there is need to increase awareness of critical nurses about knowledge and practice regarding end of life care of hepatic patients.

\section{Research hypotheses}

- Nurses posttest knowledge scores higher than nurses knowledge the pretest following implementation of teaching program.

- Nurses posttest practice scores higher than nurses pretest practice scores following implementation of teaching program.
- A positive relationexists between knowledgeand practice of critical care nurses post end of life teaching program.

\section{Subject\& Method \\ Research design}

Quasi experimental research design (pre- post test) was used to evaluate the effectiveness of structured teaching program for the present study. Thus only one group is observed twice (before and after introducing the independent variable).

Study variable

- The dependent variable was the nurse's performanceabout end of life care for hepatic patients.

- The independent variable was the teaching program.

\section{Setting}

The study was led in Tropical Intensive care units and Gastrointestinal Intensive care unit at El Raghy University Hospital

\section{Sample}

A Convenience sampling of all nurses $(n=40)$ working in above mentioned setting were included in the study the nurse must have at least one yearexperience in intensive care unit at El Raghy University Hospital and willing to participate in the study.

\section{Tools of data collection}

Two tools were used in this study

Tool one: Nurses knowledge questionnaire: this tool was develop by researcher after review literatures to evaluate knowledge level of critical care nurses about end phase of lifecare (lews, et al., 2016) \& (Lind, et al., 2011) It was converted intoarabic language This tool included two parts:

Part (1): Socio-demographic data of nurses such as: age, gender, qualification, years of experience, training course, previous working in ICU

Part (2): Nurses knowledge about hepatic disease and knowledge about end of life care for hepatic patients.

\section{Knowledge scoring system}

The tool included 12 questions; nine of them were in multiple chose questions and three open questions. Multiple chose questions scored as one degree for correct answer and zero for wrong answer. The open question scored as 2 degree for complete answer and 1 degree for incomplete answer and zero for incorrect one who obtained $50 \%$ orless thanwere considered having unsatisfactory level. While those who obtained $50 \%$ or more to were considered having satisfactory level.

Tool two: (Observational check list sheets) This tool created by researcher after review literatures (Bella \& Magnaye, 2013) used to evaluate the effect 
of teaching program on critical care nurses' practice about end of life care for hepatic patients. it consist of the 36 step as following:

- Quality care for hepatic which included 13 steps.

- Communication of nurses for patient and family which included 13 steps.

- Family support which included 6steps.

- Ethical-moral and legal responsibility which included 4steps.

\section{Practice Scoring system}

The aggregate score for all means were 36 and each progression was assessed as take after effectively done was scored (1) and not done was scored (0). Who obtained less than $50 \%$ was considered having poor practice. While those who obtained $50 \%$ or more to were considered having good practice.

\section{Development of education program}

Teaching program was created by researcher based on view of past evaluation of nurse's performance about end of life care available resources and review of relevant literature. (Sarah, 2013) \& (Judith, 2011).

\section{General goal of the teaching program:}

The general target developed teaching program to enhance the basic care nurses' knowledge and performance about end of life care for hepatic patients

\section{Preliminary stage}

- Permission to lead the study was obtained from the hospital responsible authorities after explanation the aim of the study.

- The tools used in this study were created by the researcher based on reviewing the relevant literature.

- The tools were tested for content related validity by jury of 5 specialists in the field of critical care nursing and critical care medicine.

- It was conducted on $10 \%$ of sample in selected setting to evaluate the applicability and clearly of tools, the reliability was tested for tool 1 and 2 by using Cronbach's alpha (tau-equivalent reliability) coefficient ( $r=0.827,0.859$ respectively) which its internal consistency "Good", then tools were modified according to the result of pilot study.

- A pilot study was conducted on 5 nurses to test the feasibility and applicability of the tool.Those subjects included from the actual study according to the needed modification.

- Permission for voluntary participation was obtained from nurses after explain the purpose of the study.

- An approval was obtained from the ethical committee and the study was followed the common ethical principles in clinical research.
Teaching methods

- Lectures discussion by (picture- handout).

- PowerPoint presentation and booklet which developed in arabic by the researcher based on reviewing the related literature.

- The total sample was divided into ten sub group included four nurses each session for better performance and understanding.

Implementation phase and evaluation phase

- All nurses were interviewed (one hour) in different shift or before beginning of shift.

- The total sample was divided into ten sub group includedfour nurses each session for better performance and understanding.

Assessment of knowledge was done twice as follows

- One at beginning of study was considered as pretest assessment and as base line data for latter comparison with future post test.

- The second administration of questionnaire was carried out after implementation of the teaching program to identify its effect on nurses' knowledge.

\section{Assess nurse's performance}

- The researcher observes the nurses performance using observational checklist tool two before and after program implementation

\section{Implementation of program}

The program was implemented for the ten subgroup of nurses. Allgroups were exposed to three session in addition to the preliminary one.

\section{Preliminary session}

In this session the researcher met the nurses and explained the objectives content, and methods of evaluation program.

\section{Session 1 included}

Anatomy and function of liver, definition of hepatic coma, causes of hepatic coma for duration 30 minutes.

\section{Session II included}

Causes of hepatic coma, sign and symptoms of hepatic coma, stages of hepatic coma, complication in end stage of hepatic coma, and management of hepatic coma for duration 30 minutes.

\section{Session III included}

Definition of end of life care, sign and symptoms of end of life care, and management of patient in end of life care for duration 30 minutes.

\section{Evaluation of the teaching program}

- The same pretest study tools (questionnaire sheet, observational checklist) was used as post test for study subject in order to test the effectiveness of the program on nurse's knowledge and performance about end of life care. A comparison was done between before and after program implementation. 


\section{Statistical analysis}

- The data obtained had reviewed, prepared for computer entry, coded, analyzed and tabulated. Descriptive statistics (frequencies and percentages, mean and standard deviation) were done using computer program (SPSS) version (22).

- Independent sample T-test, Chi-square and Oneway-ANOVA tests used in the relationship between pre-study and post-study groups' knowledge and practice. It's considered significant when $\mathrm{P}$. value less than (0.05).

- Cronbach's alpha was done to test reliability of the tools.

\section{Result}

Table (1): Sociodemographic characteristics of the studied nurses $(n=40)$.

\begin{tabular}{|c|c|c|}
\hline \multirow{2}{*}{ Items } & \multicolumn{2}{|c|}{ Group } \\
\hline & No. $(n=40)$ & $\%$ \\
\hline \multicolumn{3}{|l|}{ Gender } \\
\hline Male & 0 & 0.0 \\
\hline Female & 40 & 100.0 \\
\hline \multicolumn{3}{|l|}{ Age:( Years) } \\
\hline 18 to $<25$ & 23 & 57.5 \\
\hline 25 to $<35$ & 15 & 37.5 \\
\hline$>35$ & 2 & 5.0 \\
\hline Mean \pm SD & \multicolumn{2}{|c|}{$24.5 \pm 3.9$} \\
\hline Range & \multicolumn{2}{|c|}{ 21-39 } \\
\hline \multicolumn{3}{|l|}{ Education level } \\
\hline Intermediate education & 23 & 57.5 \\
\hline Technical Institute & 11 & 27.5 \\
\hline Bachelor & 6 & 15.0 \\
\hline \multicolumn{3}{|l|}{ Experience level: :( Years) } \\
\hline 1 to $<3$ & 26 & 65.0 \\
\hline 3 to $<5$ & 6 & 15.0 \\
\hline 5 to $<10$ & 1 & 2.5 \\
\hline$>10$ & 7 & 17.5 \\
\hline Mean \pm SD & \multicolumn{2}{|c|}{$4.4 \pm 3.9$} \\
\hline Range & \multicolumn{2}{|c|}{$1-14$} \\
\hline \multicolumn{3}{|l|}{ Marital status } \\
\hline Single & 23 & 57.5 \\
\hline Widow & 1 & 2.5 \\
\hline Married & 15 & 37.5 \\
\hline Divorced & 1 & 2.5 \\
\hline \multicolumn{3}{|l|}{ Training for emergency } \\
\hline Yes & 3 & 7.5 \\
\hline No & 37 & 92.5 \\
\hline \multicolumn{3}{|l|}{ Training for hepatic diseases } \\
\hline Yes & 5 & 12.5 \\
\hline No & 35 & 87.5 \\
\hline \multicolumn{3}{|l|}{ Previously worked at ICU } \\
\hline Yes & 20 & 50.0 \\
\hline No & 20 & 50.0 \\
\hline
\end{tabular}




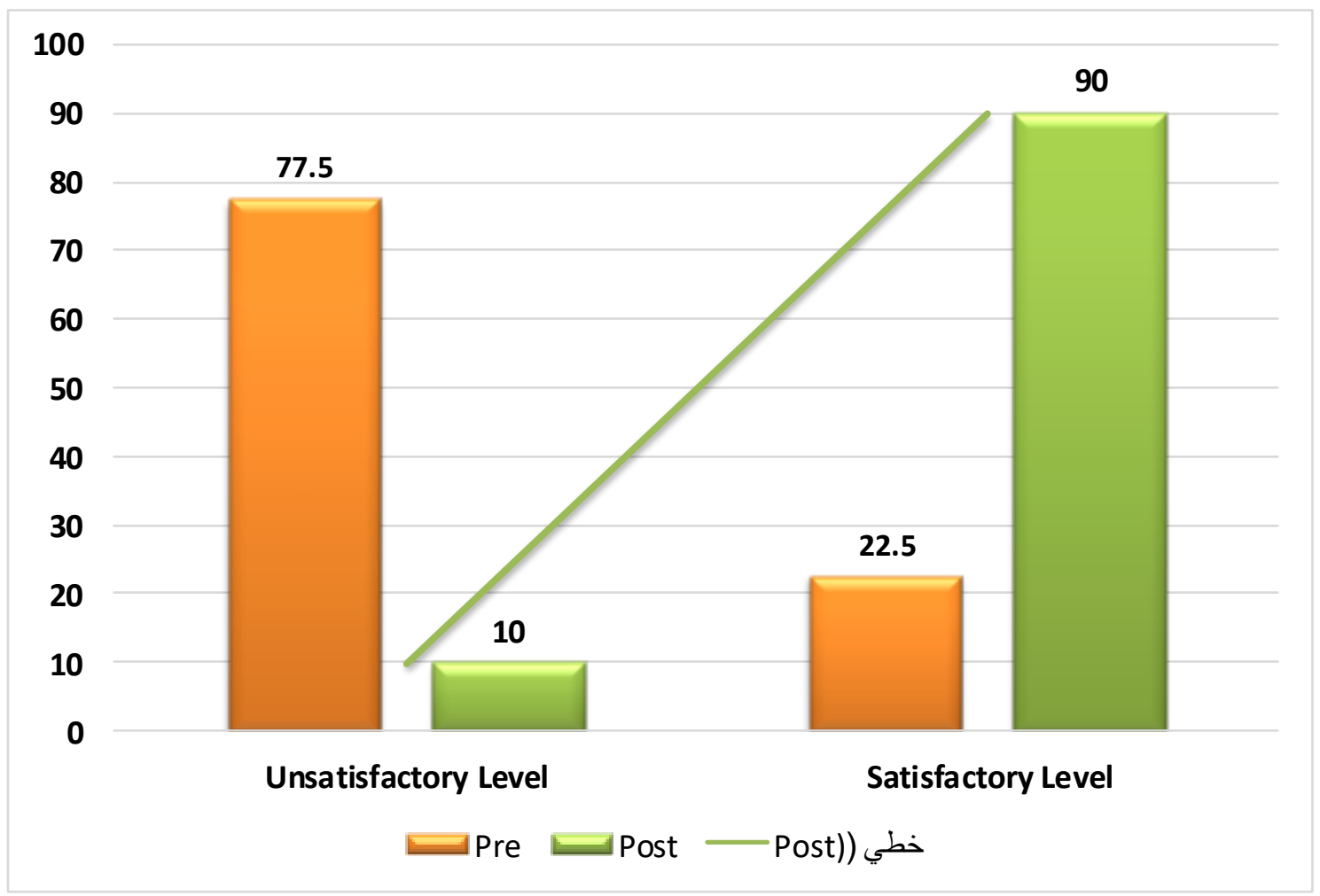

Figure (1): Percentage distribution of nurses' knowledge about end of life care.

Table (2): Percentage \&distribution of nurses' knowledge (Pre \& post - test) about end of life care.

\begin{tabular}{|c|c|c|c|c|c|c|c|c|c|c|c|c|c|}
\hline \multirow{3}{*}{ Nursing knowledge } & \multicolumn{6}{|c|}{ Pre No. 40} & \multicolumn{6}{|c|}{ PostNo. 40} & \multirow{3}{*}{ P-value } \\
\hline & \multicolumn{2}{|c|}{$\begin{array}{l}\text { Complete } \\
\text { Correct }\end{array}$} & \multicolumn{2}{|c|}{$\begin{array}{l}\text { Incomplete } \\
\text { Correct }\end{array}$} & \multicolumn{2}{|c|}{$\begin{array}{c}\text { Not } \\
\text { Correct }\end{array}$} & \multicolumn{2}{|c|}{$\begin{array}{l}\text { Complete } \\
\text { Correct }\end{array}$} & \multicolumn{2}{|c|}{$\begin{array}{l}\text { Incomplete } \\
\text { Correct }\end{array}$} & \multicolumn{2}{|c|}{$\begin{array}{c}\text { Not } \\
\text { Correct }\end{array}$} & \\
\hline & No. & $\%$ & No. & $\%$ & No. & $\%$ & No. & $\%$ & No. & $\%$ & No. & $\%$ & \\
\hline What is hepatic coma? & 18 & 45.0 & 1 & 2.5 & 21 & 52.5 & 39 & 87.5 & 0 & 0.0 & 1 & 2.5 & $0.0001 * * *$ \\
\hline What causes hepatic coma? & 18 & 45.0 & 1 & 2.5 & 21 & 52.5 & 38 & 95.0 & 0 & 0.0 & 2 & 5.0 & $0.0001^{* * *}$ \\
\hline $\begin{array}{l}\text { What are the symptoms of } \\
\text { hepatic coma? }\end{array}$ & 18 & 45.0 & 1 & 2.5 & 21 & 52.5 & 37 & 92.5 & 0 & 0.0 & 3 & 7.5 & $0.0001 * * *$ \\
\hline What is the final stage of life? & 7 & 2.5 & 1 & 2.5 & 32 & 80.0 & 21 & $52 . .5$ & 0 & 0.0 & 19 & 47.5 & $0.001 * *$ \\
\hline $\begin{array}{l}\text { Symptoms of final stage of liver } \\
\text { patients. }\end{array}$ & 10 & 25.5 & 0 & 0.0 & 30 & 75.0 & 39 & 97.5 & 0 & 0.0 & 1 & 2.5 & $0.003 * *$ \\
\hline $\begin{array}{l}\text { Common symptoms in final } \\
\text { stage of life. }\end{array}$ & 8 & 20.0 & 0 & 0.0 & 32 & 80.0 & 22 & 55.0 & 0 & 0.0 & 18 & 45.0 & $0.0001 * * *$ \\
\hline $\begin{array}{l}\text { Nursing care for patient at end } \\
\text { life care. }\end{array}$ & 34 & 85.0 & 0 & 0.0 & 6 & 15.0 & 31 & 77.5 & 0 & 0.0 & 9 & 22.5 & $0.0001 * * *$ \\
\hline $\begin{array}{l}\text { Needs of patient in the final } \\
\text { stage of life. }\end{array}$ & 21 & 52.5 & 0 & 0.0 & 19 & 47.5 & 36 & 90.0 & 0 & 0.0 & 4 & 10.0 & $0.0001 * * *$ \\
\hline $\begin{array}{l}\text { Important needs of patient's } \\
\text { life-long life. }\end{array}$ & 24 & 60.0 & 16 & 40.0 & 0 & 0.0 & 29 & 72.5 & 5 & 12.5 & 6 & 15.0 & $0.0001 * * *$ \\
\hline $\begin{array}{l}\text { To provide comfort and pain } \\
\text { relief for the patient in the final } \\
\text { stage must be: }\end{array}$ & 21 & 52.5 & 0 & 0.0 & 19 & 47.5 & 25 & 62.5 & 9 & 22.5 & 6 & 15.0 & $0.0001 * * *$ \\
\hline $\begin{array}{l}\text { To provide mental care for the } \\
\text { patient, it is necessary to: }\end{array}$ & 0 & 0.0 & 19 & 47.5 & 21 & 52.5 & 24 & 60.0 & 11 & 27.5 & 5 & 12.5 & $0.0001^{* * * *}$ \\
\hline $\begin{array}{l}\text { Deal with liver patient in the } \\
\text { final stage? }\end{array}$ & 0 & 0.0 & 7 & 17.5 & 33 & 82.5 & 22 & 55.5 & 12 & 30.0 & 6 & 15.0 & $0.0001 * * *$ \\
\hline
\end{tabular}

Independent sample T test

* Statistical significant differences $(p \leq 0.001)$ 


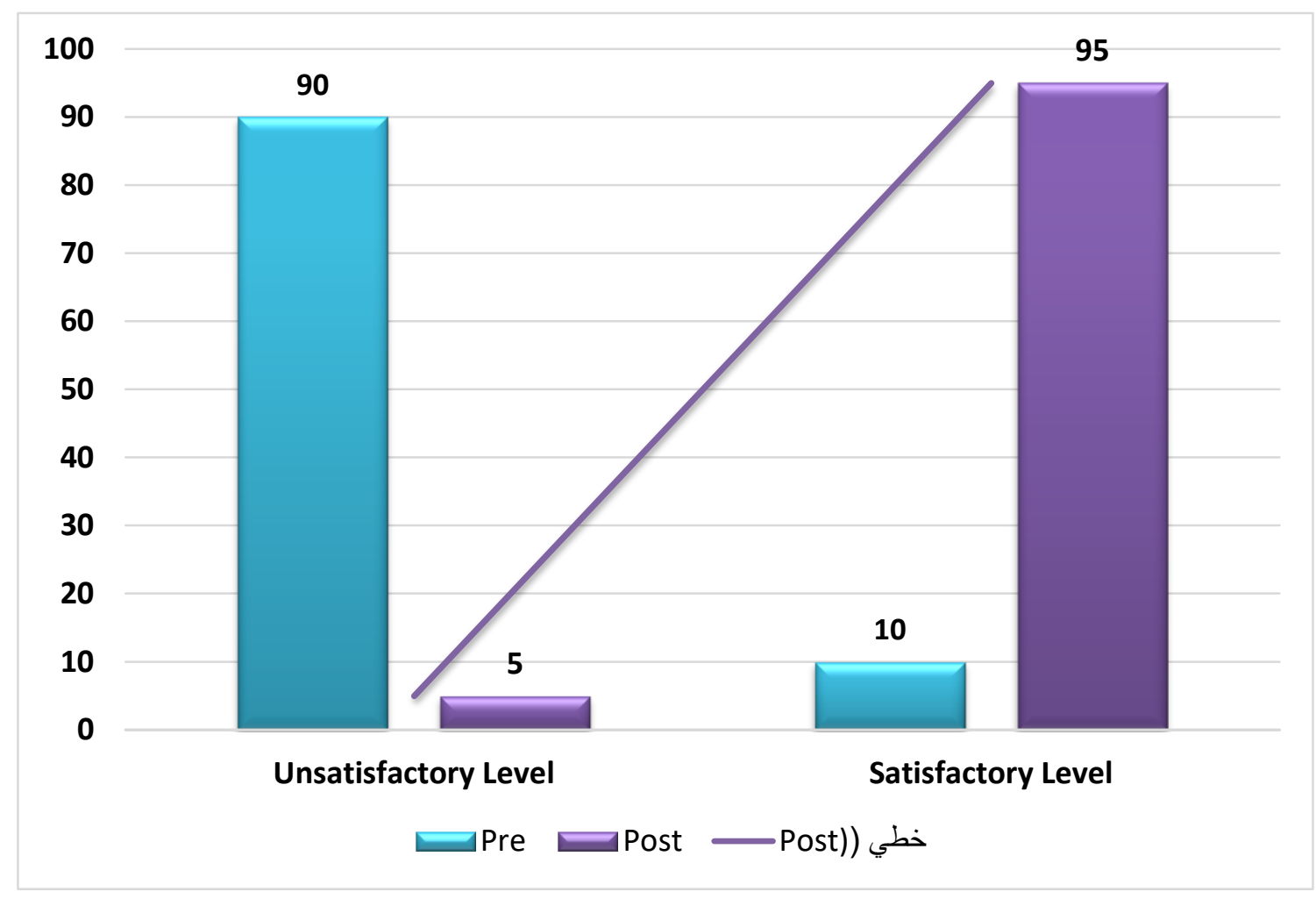

Figure (2): Percentage distribution of nurses' practice about end of life care.

Independent sample T-test

* Statistical significant differences $(p<0.05)$

Table (3): Percentage \&distribution of nurses' Practice regarding quality care (Pre \& post - test).

\begin{tabular}{|c|c|c|c|c|c|c|c|c|c|}
\hline \multirow{3}{*}{ Quality care Nursing practice } & \multicolumn{4}{|c|}{ Pre No. 40} & \multicolumn{4}{|c|}{ PostNo. 40} & \multirow{3}{*}{ P-value } \\
\hline & \multicolumn{2}{|c|}{ Done } & \multicolumn{2}{|c|}{ Not Done } & \multicolumn{2}{|c|}{ Done } & \multicolumn{2}{|c|}{ Not Done } & \\
\hline & No. & $\%$ & No. & $\%$ & No. & $\%$ & No. & $\%$ & \\
\hline Assess vital signs. & 39 & 97.0 & 1 & 2.5 & 40 & 100.0 & 0 & 0.0 & 0.320 \\
\hline Perform infection control measures. & 11 & 27.5 & 29 & 72.5 & 40 & 100.0 & 0 & 0.0 & $0.0001 * * *$ \\
\hline $\begin{array}{l}\text { Assess pain frequently and administer } \\
\text { analgesics. }\end{array}$ & 28 & 70.0 & 12 & 30.0 & 40 & 100.0 & 0 & 0.0 & $0.0001 * * *$ \\
\hline Instruct relatives about infection control. & 1 & 2.5 & 39 & 97.5 & 20 & 50.0 & 20 & 50.0 & $0.0001 * * *$ \\
\hline Ensure clients' safety by raising side rails. & 30 & 75.0 & 10 & 25.0 & 24 & 60.0 & 16 & 40.0 & 0.156 \\
\hline $\begin{array}{l}\text { Provide the client with mean to call for } \\
\text { assistance. }\end{array}$ & 11 & 27.5 & 29 & 72.5 & 16 & 40.0 & 24 & 60.0 & 0.234 \\
\hline $\begin{array}{l}\text { Perform frequent turning and positioning of } \\
\text { client. }\end{array}$ & 29 & 72.5 & 11 & 27.5 & 40.0 & 100.0 & 0 & 0.0 & $0.0001 * * *$ \\
\hline Position client to semi flowers position. & 37 & 92.5 & 3 & 7.5 & 40 & 100.0 & 0 & 0.0 & 0.079 \\
\hline Provide oral hygiene as often as necessary. & 36 & 90.0 & 4 & 10.0 & 40 & 100.0 & 0 & 0.0 & $0.041 *$ \\
\hline $\begin{array}{l}\text { Ensure patient is not lying or sitting on } \\
\text { equipment. }\end{array}$ & 35 & 87.5 & 5 & 12.5 & 31 & 77.5 & 9 & 22.5 & 0.245 \\
\hline Encourage talking to/touching patient. & 10 & 25.0 & 30 & 75.0 & 27 & 67.5 & 13 & 32.5 & $0.0001 * * *$ \\
\hline Locate private place for family communication. & 0 & 00.0 & 40 & 100.0 & 40 & 100.0 & 0 & 0.0 & $0.0001 * * *$ \\
\hline $\begin{array}{l}\text { Nurse not being able to communicate with } \\
\text { patient. }\end{array}$ & 40 & 100.0 & 0 & 0.0 & 40 & 100.0 & 0 & 0.0 & - \\
\hline
\end{tabular}


Table (4): Percentage \&distribution of nurses' Practice regarding communication (Pre \& post - test).

\begin{tabular}{|c|c|c|c|c|c|c|c|c|c|}
\hline \multirow{3}{*}{ Communication Nursing practice } & \multicolumn{4}{|c|}{ Pre No. 40 } & \multicolumn{4}{|c|}{ PostNo. 40 } & \multirow{3}{*}{ P-value } \\
\hline & \multicolumn{2}{|c|}{ Done } & \multicolumn{2}{|c|}{ Not Done } & \multicolumn{2}{|c|}{ Done } & \multicolumn{2}{|c|}{ Not Done } & \\
\hline & No. & $\%$ & No. & $\%$ & No. & $\%$ & No. & $\%$ & \\
\hline $\begin{array}{l}\text { Encourage sharing feelings for client and his } \\
\text { family. }\end{array}$ & 1 & 2.5 & 39 & 97.5 & 26 & 65.0 & 14 & 35.0 & $0.0001 * * *$ \\
\hline Discuss about patients plan of care. & 0 & 0.0 & 40 & 100.0 & 24 & 60.0 & 16 & 40.0 & $0.0001 * * *$ \\
\hline Take and address with the patient's family. & 0 & 0.0 & 40 & 100.0 & 18 & 45.0 & 22 & 55.0 & $0.0001 * * *$ \\
\hline $\begin{array}{l}\text { Use simple term instead of complex medical } \\
\text { language. }\end{array}$ & 39 & 97.5 & 1 & 2.5 & 40 & 100.0 & 0 & 0.0 & 0.320 \\
\hline Nurse having to deal with angry family members. & 0 & 0.0 & 40 & 100.0 & 38 & 95.0 & 2 & 5.0 & $0.0001 * * *$ \\
\hline Talk with the family about it being all right. & 0 & 0.0 & 40 & 100.0 & 24 & 60.0 & 16 & 40.0 & $0.0001 * * *$ \\
\hline Talk with the family about the patient's illness. & 2 & 5.0 & 38 & 95.0 & 37 & 92.5 & 3 & 7.5 & $0.0001 * * *$ \\
\hline $\begin{array}{l}\text { Helping family understand what the dying } \\
\text { process. }\end{array}$ & 0 & 0.0 & 40 & 100.0 & 26 & 65.0 & 14 & 35.0 & $0.0001 * * *$ \\
\hline Giving bad news in a sensitive way. & 15 & 37.5 & 25 & 62.5 & 26 & 65.0 & 14 & 35.0 & $0.014^{*}$ \\
\hline Family continually calls nurse for update. & 33 & 82.5 & 7 & 17.5 & 30 & 75.0 & 10 & 25.0 & 0.419 \\
\hline Nurse having to deal with angry family members. & 3 & 7.5 & 37 & 92.5 & 40 & 100.0 & 0 & 0.0 & $0.0001 * * *$ \\
\hline Family members not having private place. & 9 & 22.5 & 31 & 77.5 & 29 & 72.5 & 11 & 27.5 & $0.0001 * * *$ \\
\hline Family not with the patient when he/she is dying. & 30 & 75.0 & 10 & 25.0 & 40 & 100.0 & 0 & 0.0 & $0.001 * *$ \\
\hline
\end{tabular}

Table (5): Percentage \&distribution of nurses' practice regarding family support (Pre \& post - test).

\begin{tabular}{|c|c|c|c|c|c|c|c|c|c|}
\hline \multirow{3}{*}{ family support Nursing practice } & \multicolumn{4}{|c|}{ Pre No. 40} & \multicolumn{4}{|c|}{ PostNo. 40 } & \multirow{3}{*}{ P-value } \\
\hline & \multicolumn{2}{|c|}{ Done } & \multicolumn{2}{|c|}{ Not Done } & \multicolumn{2}{|c|}{ Done } & \multicolumn{2}{|c|}{ Not Done } & \\
\hline & No. & $\%$ & No. & $\%$ & No. & $\%$ & No. & $\%$ & \\
\hline Having family time to be alone with patient. & 39 & 97.5 & 1 & 2.5 & 37 & 92.5 & 3 & 7.5 & 0.311 \\
\hline Allowing family unlimited access to patient. & 0 & 0.0 & 40 & 100.0 & 16 & 40.0 & 24 & 60.0 & $0.0001 * * *$ \\
\hline Give reports on the state of the patient & 3 & 7.5 & 37 & 92.5 & 32 & 80.0 & 8 & 20.0 & $0.0001 * * *$ \\
\hline Urge relatives to contribute. & 1 & 2.5 & 39 & 97.5 & 33 & 82.5 & 7 & 17.5 & $0.0001 * * *$ \\
\hline Providing the opportunity for dialogue. & 15 & 37.5 & 25 & 62.5 & 35 & 87.5 & 5 & 12.5 & $0.0001 * * *$ \\
\hline $\begin{array}{l}\text { Setting aside opportunity to tune in, concerns and } \\
\text { answer questions. }\end{array}$ & 24 & 60.0 & 16 & 40.0 & 34 & 85.0 & 6 & 15.0 & $0.012 *$ \\
\hline
\end{tabular}

Independent sample T test.

* Statistical significant differences $(p \leq 0.05)$

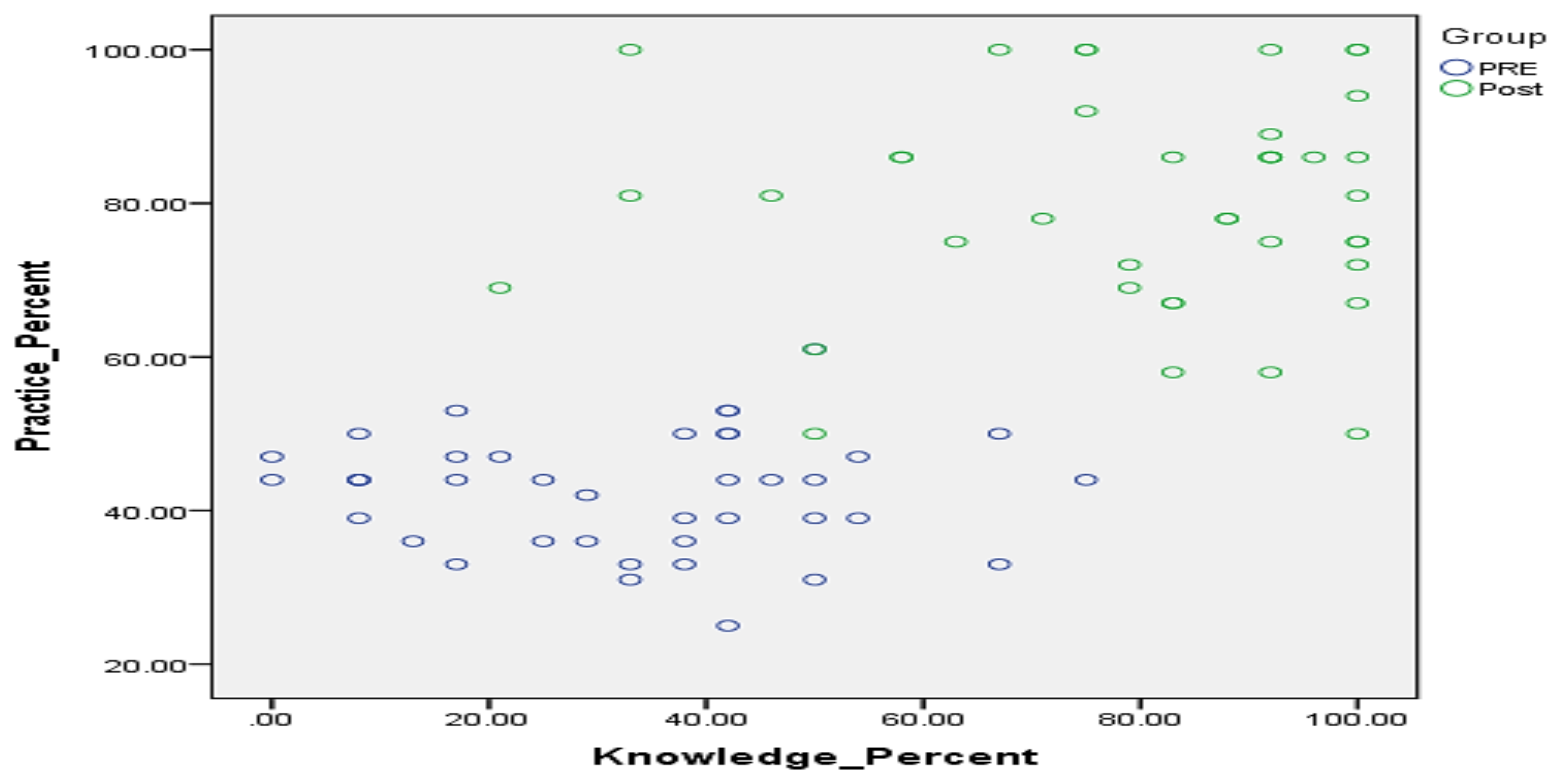

Figure (3): relationship between nurses' pre-post knowledge and pre-post practice: 
Table (1): Shows that all groups were female with percentage $100 \%$. More than half of group had aged between 18 to < 25years and had intermediate education single with percentage $57.5 \%$.Two third of group had 1 to $<3$ years of experience with percentage $65.0 \%$. Most of group hadn't training for emergency or for hepatic diseases with percentage $92.5 \%$ and $87.5 \%$ respectively. Half of group had previously worked at ICUwith percentage $50 \%$.

Table (2): Reflected that All items of nurses' knowledge (Pre \& post - test) had a very highly statistical difference with p-valuerespectively $(0.001$ and 0.003 ) except at final stage of life? \&Symptoms of final stage of liver patients.

Table (3): Illustrates that Most item of nurses' practice (pre \& post - test) regarding Quality care had very highly statistical difference between nurses' Pre and Post practice according to total degree with $\mathrm{p}$ value (0.0001).

Table (4): Illustrates that Most item of nurses' practice (pre \& post - test) regarding Communication had very highly statistical difference between nurses' Pre and Post practice according to total degree with p-value (0.0001).except family continually care nurses for update and used support termwith $\mathrm{p}$-value $(0.41,0.32)$.

Table (5) Illustrates that Most item of nurses' practice (pre \& post - test) regarding Family support had very highly statistical difference between nurses' Pre and Post practice according to total degree with $\mathrm{p}$-value (0.0001).At (Taking time to listen, concerns and answer questions.) there is statistical difference between nurses' Pre and Post practice according to total degree with p-value (0.012).

Figure (1): Show that There is very highly statistical difference between nurses' knowledge between Pre \&Post test. The most of nurses had unsatisfactory level pre-knowledge; also most of Post Study group had satisfactory level.

Figure (2): Show that there is very highly statistical difference between nurses' Pre \& Post practice according to total degree with p-value (0.0001).

Figure (3): Illustrates that there is a relation between nurses' pre-post knowledge and pre-post practice on one hand by increasing the knowledge (post-test) the practice will be better and on other hand by decreasing the knowledge (pre-test) the practice will be worst.

\section{Discussion}

Based on the results of the present study, most ofnurses were young adults. A large portion of them have no in-serves instructional classes identified with end of life for hepatic patients and the greater part of study were had 1 , 3years of experience and more than of study group worked at ICU.
This findings agree with, (Zaghla, et al., 2014)who reported the Knowledge \& Practice of Nurses about End of Life Nursing Care which revealed that majority of the study subjects were females, less than thirty years old with mean age $(24.21 \pm 4.38)$, were bed side nurse, and didn't have any training related to end of life nursing care. Also the highest percentages of the study sample were having five to ten years of experience.

In this line, (Wahdan, 2010)who reported that revealed nearly half of the study subjects were at age group of 20 to 25 years old, total sample was females, had five years' experience in critical care units or more, also held a diploma degree, and were bedside nurse.

The current study documented poor perception on end of life care, death and dying. One of the reasons could be due to lack of experience with majority of nurses have less than 1 year experience and below 30 years old. (Subramanian, 2013).

The present study showed very highly statistical difference nurses' knowledge between Pre \&Post test. The most of nurses had unsatisfactory level preknowledge Also most of Post Study group had satisfactory level.This may be due to deficiency of nurses knowledge especially whom working in the intensive care units and increase the number of patients for each nurse with over-loaded by more duties and having more work hours.

This finding agree with the current study, Nelson, and Kirchhoff (2009), revealed that nurses have identified a need for improving their knowledge and skills in giving end of life care. In this respect, Meg \&Mary (2010) mentioned that the nurse'sattendants detailed because of their absence of knowledge, autonomy, and support with providing end of life care in intensive care units. (Hansen, et al., 2009).

According to Barbara (2008), 39\% of nurses $(n=27)$ reported that they had not had any end of life education in their nursing school curriculum and the $61 \%$ that did rate the quality of that education on a scale of 1-10 with the mean of $6.70 \%$ reported that they had never received any continuing education on end of life since graduating from nursing school. (Morgan, 2008).

The current study revealed, recognizing issues of lacking knowledge and inappropriate attitudes related to pain management are of concern. A better understanding of the factors that impact such knowledge and attitudes and of the difference between attitudes and practice can provide beneficial information to be included in education programmers for nurses and to know policy on the relief of pain management.(Liza, 2008).

This is in the line with (Debra, 2014) revealed that effectively implement the ELNEC (End-of-Life Care 
Education in Acute and Critical Care) standardized curriculum into a hospital environment and evaluate the impact on voluntary nurse participants Findings indicate this intervention did result in a statistically significant change. Nurses demonstrated increased knowledge of EOL care. The nurses post intervention results on the ELNEC (End-of-Life Care Education in Acute and Critical Care) were demonstrated an increased knowledge of end of life care.

In accordance with Canadian association of basic critical care nurse in the last position statement on providing end of life care in ICU revealed that nurses in critical care need require openings through education and mentoring to build up their competency in giving end-of-life care around the areas of: Communications skills to abilities to advocate for patients and families,, standardized approaches to deal with pain and symptom management and looking for and giving emotional support help to patients, families and individuals from medicinal services group including the nurse (Nelson, 2006).

After implementation of the teaching program, nurses practice score levels about end of life care were significantly improved. This improvement might be related to the fact that most of nurses were in young age this age might have good readiness for learning new things.

This finding agree with the current study role of critical care nurses in endof life care which detect that Nurses generally are expert in performance endoflife care to terminally ill clients. Among the five standards established by the AACN (American association of critical care nurses) in Critical Care nursing, Education had the least priority since it is more focused on the nurses' personal and professional development and is believed to have an indirect effect to the patients' prognosis (Bella, 2013).

The current study revealed the highlights the important role of critical care nurses in endoflife decision making. Although nurses believe that their involvement is beneficial to patients and family members, this paper strengthens the requirement for experimental evidence of these benefits at the end of life, especially as it relates to the well-being and coping of family members who are making difficult decisions about a loved one in an acute care environment. (Judith, et al., 2011).

This is line with documented that The ELNEC$\mathrm{CC} /$ Archstone courses were successful in increasing the palliative or EOL care knowledge and perceived effectiveness in teaching palliative care/EOL content for acute and critical care nurses who completed this course, which is similar to the benefits of ELNEC courses for nurses in other areas. (Marian 2013).
(Hyun, et al., 2011) revealed after come to the course. the knowledge of hospice and palliative care expanded among all groups, particularly significantly higher for the group of nurses never ensured in hospice and palliative nursing. Overall, the End-ofLife Nursing Education Consortium course was successful for Korean nurses in increasing the knowledge on hospice and palliative care.

(Daren 2010)revealed End-of-life care in Canada might be enhanced for patients and their families by giving better psychological and spiritual support, better planning of care and improved relationships with physicians, especially in aspects related to communication and decision-making.

This is line with (Krimshtein, et al., 2011) Effective communication is an essential component of highquality care in the ICU. Evidence propose that communication with patients and families in the ICU can be most effectively approached in an interdisciplinary way and they must be equipped with the necessary skills. And evidence-based training program such as useful educational strategy for developing ICU nurses' communication expertise and prepares them to be more active members on the interdisciplinary team.

\section{Conclusion}

The current study evaluates effect of an Educational program on critical care nurses' knowledge and performance about end of life care for hepatic patients. Based on the results of this study, it can be concluded that:

- A statistical significant difference was found between the critical Care nurses' level of knowledge before, immediately after application of teaching program about end of life care for hepatic patients.

- A statistical significant improvement was found between the critical Care nurses' level of practice before immediately after application of teaching program regarding end of life care for hepatic patients.

- There is relation found between knowledge and practice score.

\section{Recommendations}

Based on the finding of the present study, the studies recommend that are recommending

- Educate and encourage nurses to communicate directly, in a more open manner, with each other and with patients and patients' families.

- Organize family meetings frequently to discuss concerns review diagnoses, prognoses, and plan of care 
- Periodic monitoring of nurses knowledge and practice by nursing audits and supervisors.

- A continuing educations program be planned for and offered on regular basis to nurses in Emergency Unit.

- Nurses should be encouraged to go to particular gatherings as workshops and courses held for end of life care to be acquainted with the most advances and skills in this area.

- Returnthis research on large sample size and in various settings for generalization.

\section{Reference}

1. Bach, V, Ploeg, J., Black, M.,(2011). Nursing roles in end-of-life decision-making in critical care settings. Western Journal of Nursing Research, 31(4), pp. $496-512$.

2. Bella P. Magnaye R, (2013), International Scientific Research Journal, Volume 6 Issue 3.pp193-205

3. . Byass P, 2014. The global burden of liver disease: a challenge for methods and for public health.

4. Calvin A., Lindy O, Clingon, S, L (2009) Nurse's experience with end-of life Care in Intensive and Critical Care Nursing, vol. 25, no. 4, pp. 214-220.

5. D'Amico G, Garcia-Tsao G, Pagliaro L, (2012).Natural history and prognostic indicators of survival in cirrhosis pp.217-231.

6. Daren K,Heyland, M, Deborah J. Cook, , Graeme M. Rocker, D, Peter M. Dodek, M, Demetrios J. KutsogiannisM, YoannaSkrobik, , Xuran Jiang, M , Andrew G. \& Robin Cohen, $P$ (2010), Defining priorities for improving endof-life care in Canada, vol 9. P182.

7. -Debra J, (2014). Evaluation of Impact of EndOf-Life Nursing Education Consortium (Elnec) Education on Registered Nurses, Journal of the Academy of Medical-Surgical Nurses, 23(1), PP: 35-43.

8. DunwoodyC.J, D.A. Krenzischek, C.Paser C, Rathmell J, \& Polomano R. (2008) Assessment, physiological monitoring, and consequences of inadequately treated acute pain, pp. 515-527,

9. -ZaghlaH,,.Yossef W,ALi D.\&Salime $\quad \mathbf{R}$ Salime, M(2014) Knowledge and Practice of Nurses about End of Life Nursing Care for Critically Ill Patients, Cairo University Hospital.

10. -Hasnen L, Goodell T, Haven J. and Smith M (2009): Nurses' perceptions of end-of-life care after multiple interventions forimprovement. American Journal of Critical Care, 18 (3): 263-71,
11.-Hyun S, HeeJu (2011), journal of Hospice \& Palliative Nursing: July/August 2011 - Volume 13 - Issue 4 - pp. 222-229

12. Judith A, Donald E. Bailey, J, Ruth A. Anderson, \& Sharron L. Docherty (2011). Nursing Roles and Strategies in End-of-Life Decision Making in Acute Care, Nursing Research and Practice vol. 20, no. 3, pp. 525-540.

13. Khaled E. Amer\& Ibrahim M (2016): Living donor liver transplantation in Egypt, VOL (5). No (2), pp. 98- 106.

14. Lew,B,HeitkemR, (2016) medical surgical nursing assessment and management of critical problems, 10th edition, Evolve Elsevier, chapter(9) palliative care and end of life care, pp.146-149.

15. LindR., Lorem G, Nortvedt P, LimerickM\&Hevrøy O (2011) "Family members' experiences of "wait and see" as a communication strategy in end-of-life decisions," Intensive Care Medicine, vol. 37, no. 7, pp. 11431150.

16. Liza Y (2008) Knowledge and attitudes regarding pain management among nurses in Hong Kong medical units.

17. Marian G ,Wiencek C, Virani R, Uman G, MunevarC( 2013), End-of-Life Care Education in Acute and Critical Care, American Association of Critical-Care Nurse, volume 24 .Number 2 PP121-129.

18. Mary H , Joanne G, JoAnne G, Caroline O (2014)Nursing care for patients at end of life in the adult intensive care unit, Journal of Nursing Education and Practice, Vol.4,No.6 pp2255-2262.

19. Moore K, Sharon N. SanchezW, Talwalkar J. (2012), BritishAssociation for the Study of the Liver and British Society of Gastroenterology, Living and dying well with end-stage liver disease, pp. 674-680.

20. Morgan. J, Bailly N, Perrier M, Bougle M, Colombat C.(2008) British Association of Critical Care Nurses, Vol 13 No 3 End-of-life care in UK critical care units-a literature review. pp. 152-161.

21. Nelson J, Angus D., Weissfeld L, PuntIllok A\&Danis M (2006) End-of-life care for the critically ill: A national intensive care unit survey. Critical Care Med, 34 (10) pp. 2547-2553.

22. KrimshteinN, Carol A. Luhrs, M, Kathleen A. Puntillo R, Therese B. Cortez M , Elayne E. Livote M, Joan D. Penrod P, Judith E\& NelsonM (2011), Training Nurses for Interdisciplinary Communication with Families in the Intensive Care Unit: An Intervention, Journal of Palliative Medicine, vol14) No (12) PP.13251332. 
23.Sarah E.shananon P, John SM , Jared R, Curtis M \& Ardith D (2013).Journal of Hospice $\&$ Palliative Nursing, Volume 15 Number 4 , The transition to End of life care in End-Stage Liver Disease, pp209 -215

24.Subramanian, P. \& Chinna K (2013) International Journal of Scientific Research Volume-7 Issue5, knowledge and perception on End of life care, death and dying among palliative nurses, pp 287-288. 